Cite this: Phys. Chem. Chem. Phys., 2014, 16, 4039

Received 25th October 2013, Accepted 3rd January 2014

DOI: $10.1039 / c 3 c p 54514 h$

www.rsc.org/pccp

\title{
The reactions of Criegee intermediates with alkenes, ozone, and carbonyl oxides $\dagger$
}

\author{
L. Vereecken, * H. Harder and A. Novelli
}

\begin{abstract}
The reaction of Criegee intermediates with a number of coreactants is examined using theoretical methodologies, combining $\mathrm{ROCCSD}(\mathrm{T}) / / \mathrm{M} 06-2 \mathrm{X}$ quantum calculations with theoretical kinetic predictions of the rate coefficients. The reaction of $\mathrm{Cl}$ with alkenes is found to depend strongly on the substitutions in the reactants, resulting in significant differences in the predicted rate coefficient as a function of the selected alkene and $\mathrm{Cl}$. Despite submerged barriers, these entropically disfavored reactions are not expected to affect $\mathrm{Cl}$ chemistry. The reaction of $\mathrm{H}_{2} \mathrm{COO}+\mathrm{H}_{2} \mathrm{COO}$ is found to be barrierless, with a rate coefficient nearing the collision limit, $\geq 4 \times 10^{-11} \mathrm{~cm}^{3}$ molecule $\mathrm{c}^{-1}$. The dominant reaction products are expected to be carbonyl compounds and an oxygen molecule, though chemically activated reactions may give rise to a plethora of different (per)acids and carbonyl compounds. $\mathrm{Cl}+\mathrm{Cl}$ reactions are expected to be important only in laboratory environments with high $\mathrm{Cl}$ concentrations. The reaction of $\mathrm{H}_{2} \mathrm{COO}$ with $\mathrm{O}_{3}$ was predicted to proceed through a pre-reactive complex and a submerged barrier, with a rate coefficient of $1 \times 10^{-12} \mathrm{~cm}^{3}$ molecule $\mathrm{s}^{-1}$. A study of the dominant $\mathrm{Cl}$ reactions under experimental and atmospheric conditions shows that the latter reaction might affect $\mathrm{Cl}$ chemistry.
\end{abstract}

\section{Introduction}

Carbonyl oxides, also known as Criegee intermediates (CI), are key intermediates in the ozonolysis of unsaturated compounds in the atmosphere. Despite being proposed as early as 1949,, their characterisation has long been hampered by a lack of suitable detection methods, and until recently most experimental information was highly indirect. The ozonolysis reaction is complex, where the CI formed partially undergo chemically activated reactions, while the remainder is either formed with thermal energy content or is stabilized by collisional energy loss. This further complicates their study. The importance of CI in the atmosphere, ${ }^{3-7}$ not only as an intermediate in the ozonolysis but also as a source of $\mathrm{OH}$, an oxidant for $\mathrm{SO}_{2}$ and $\mathrm{NO}_{2}$, and possibly other contributions to tropospheric chemistry, warrants extensive investigations of the chemistry of stabilized CI (SCI).

Since the first detection of $\mathrm{H}_{2} \mathrm{COO}$, the smallest CI, by Taatjes et al. in $2008,{ }^{8}$ a large set of experimental data on CI and their chemistry has become available $;^{9-18}$ we refer to the recent review paper by Taatjes et $a l^{3}$ for a detailed discussion. Theoretical analysis has played a significant role in our understanding of CI, amplified further by the historical dearth of experimental data.

Max Planck Institute for Chemistry, Hahn-Meitner-Weg 1, 55128 Mainz, Germany. E-mail: Luc.Vereecken@mpic.de

$\dagger$ Electronic supplementary information (ESI) available. See DOI: 10.1039/ c3cp54514h
The recent review by Vereecken and Francisco ${ }^{19}$ discusses the many available theory-based literature in detail. Since then, more relevant theoretical studies have been published, including work on the $\mathrm{CI}+\mathrm{O}_{3}$ reaction $^{20}$ and the $\mathrm{CI}+$ carbonyl reaction. $^{21}$ Many reactions of CI remain poorly understood, but are essential for the interpretation of experimental data, both in field and laboratory. In this work, we study a number of reactions that are likely to affect laboratory work, and possibly contribute to CI chemistry in the atmosphere. The reactions studied were chosen based on the expected chemistry of the CI as determined by its complex 1,3-dipole character. The dominant contributing configurations in this wavefunction are shown below, in decreasing order of importance, and are critical in the understanding of CI chemistry:

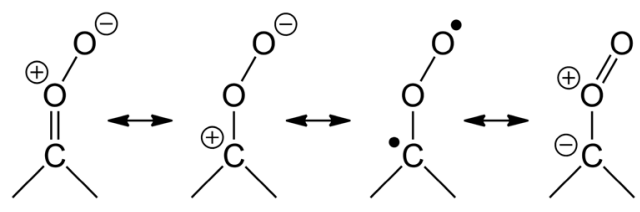

Contrary to older assumptions, ${ }^{22}$ CI are now known to be mostly zwitterionic ${ }^{14,18,19}$ with a relatively low contribution of biradical character. As a 1,3-bipole, it is expected to react similar to ozone, which has a similar zwitterionic structure with negatively charged outer oxygen atoms, and a positively charged central O-atom: 


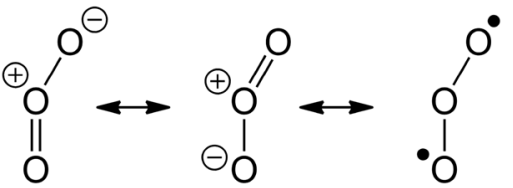

Ozonolysis of alkenes is a well-known process in the atmosphere, and CI are expected to display similar reactivity to olefines. Theoretical work by Crehuet et $a .^{23}$ and Lan et $a .^{24}$ showed these reactions to have lower barriers to reaction compared to the analogous ozonolysis; these reactions might therefore have higher rate coefficients and CI-initiated oxidation of alkenes could contribute even at lower concentrations of CI. This is particularly true in laboratory studies, where reactants are often used in higher concentrations than VOC and oxidants in the atmosphere; ${ }^{25}$ evidence for $\mathrm{CI}+$ olefines was already reported as early as 1967 by Story and Burgess. ${ }^{26}$

In their ground-breaking experiments on the infrared detection of $\mathrm{CI}, \mathrm{Su}$ et al. ${ }^{14}$ observed fast $\mathrm{H}_{2} \mathrm{COO}$ loss on the order of microseconds; they proposed that this decay is governed by fast $\mathrm{CI}+\mathrm{CI}$ reactions driven by their relatively high $\mathrm{H}_{2} \mathrm{COO}$ concentrations. We investigate the $\mathrm{H}_{2} \mathrm{COO}+\mathrm{H}_{2} \mathrm{COO}$ reaction in this work. If this 1,3-dipole +1,3-dipole reaction is fast, it is worthwhile to also examine the $\mathrm{CI}+\mathrm{O}_{3}$ reaction. The analogous $\mathrm{O}_{3}+\mathrm{O}_{3}$ reaction is known to be slow, but recent work by Kjaergaard et $a .^{20}$ showed the $\mathrm{CI}+\mathrm{O}_{3}$ reaction to be possibly barrierless. Computational difficulties prevented them from recommending a rate coefficient, and they propose a lower limit on the $\mathrm{H}_{2} \mathrm{COO}+\mathrm{O}_{3}$ rate coefficient of $10^{-18} \mathrm{~cm}^{3}$ molecule $\mathrm{e}^{-1} \mathrm{~s}^{-1}$.

The intent of this paper is to explore the listed set of SCI reactions and assess their possible relevance in the atmosphere and lab, rather than aiming at the most accurately possible characterization of a particular reaction. As such, the levels of theory chosen are not necessarily the highest levels of theory available, though they are expected to yield a good description of the reaction mechanism, and allow for a quantitative analysis that is sufficiently accurate for our current purposes. Improved calculations for the most critical of the reactions studied here are in progress, and experimental verification remains necessary. Extensive ESI $\dagger$ is available; tables and figures in the $\mathrm{ESI} \dagger$ are numbered with an SI-prefix.

\section{Methodology}

\section{a. Quantum chemical calculations}

The geometries of all structures are optimized using the M06-2X density functional ${ }^{27}$ combined with the Dunning ${ }^{28}$ aug-cc-pVDZ or aug-cc-pVTZ basis set (denoted M06-2X/aVxZ, with $\mathrm{x}=\mathrm{D}$ or T). Harmonic vibrational wavenumbers were obtained at the same level of theory, and scaled by a factor of $0.971 .{ }^{29,30}$ All M06-2X calculations used an ultrafine integration grid, and very tight SCF convergence criteria. For a subset of intermediate structures, the relative energies were improved by single point ROHF/ $\mathrm{UCCSD}(\mathrm{T})$ calculations on the M06-2X geometries, employing aug-cc-pVDZ, aug-cc-pVTZ and aug-cc-pVQZ Dunning basis sets (denoted as $\operatorname{CCSD}(\mathrm{T}) / \mathrm{aVxZ}$ hereafter); extrapolation to an infinite basis set uses the Schwartz schemes proposed by Martin. ${ }^{31}$ The electronic wavefunctions of $\mathrm{CI}$ and $\mathrm{O}_{3}$ intrinsically have multireference character, where the dominant contributing Lewis structures are depicted above. Single-reference methodologies as employed here, however, are usually found to perform adequately. ${ }^{19}$ For CI, broken-symmetry ${ }^{32}$ unrestricted SCF wave functions converged to the dominant zwitterionic closed shell wavefunction, yielding the same results as for restricted spin singlet calculations. For ozone, open-shell singlet M06-2X calculations yield a spin density separation across the outer oxygen atoms, which implies a stronger contribution of the bi-radical component in the wavefunction; $S^{2}$ remains $<0.01$ after annihilation of the first spin contaminant. For the reactions of $\mathrm{CH}_{2} \mathrm{OO}$ with $\mathrm{CH}_{2} \mathrm{OO}$ and $\mathrm{O}_{3}$, the subsequent chemistry involves singlet bi-radicals; these were likewise characterized using brokensymmetry SCF. As most of these bi-radicals have independent radical sites, it is expected that their singlet and triplet spin states have near-identical energies and properties; we therefore compared the optimized singlet and triplet bi-radical spin states, which serves as a further confirmation the singlet state was characterized correctly. For some of the biradical structures, we were unable to obtain open-shell ROHF wavefunctions for use in the $\operatorname{CCSD}(\mathrm{T})$ calculations, or were unable to get the CCSD calculations to converge owing to deficiencies in the ROHF wave function. For these structures, we don't report $\operatorname{CCSD}(\mathrm{T})$ results; note that singlet UHF are severely spin-contaminated, with $S^{2}$ as high as 3 after annihilation of the first spin contaminant rather than the expected 0.0 value, and should not be used as a reference wavefunction. The T1 diagnostics, a measure of the multi-reference character of a compound, are listed in the ESI, $\dagger$ and differ significantly across the structures investigated, even for similar TS. This indicates that the multi-reference character of the wavefunction varies significantly and the use of singlereference methods might prove to be less accurate for some reactions. Generally, T1 values above 0.044 are considered to yield unreliable results. ${ }^{33}$

All DFT calculations, and the $\operatorname{ROCCSD}(\mathrm{T})$ calculations for $\mathrm{CI}+\mathrm{CI}$ and $\mathrm{CI}+\mathrm{O}_{3}$ were done using Gaussian-09; ${ }^{34} \mathrm{ROHF} /$ UCCSDT calculations for CI + alkene were performed using the Molpro-2010.1 program. ${ }^{35}$ The ball-and-stick models were generated using Jmol. ${ }^{36}$

\section{b. Theoretical kinetic calculations}

The rate coefficient for $\mathrm{CI}$ addition to alkenes, and for the addition of $\mathrm{O}_{3}$ to $\mathrm{CH}_{2} \mathrm{OO}$ was calculated using canonical transition state theory (TST), in a rigid rotor harmonic oscillator approximation. The reaction entropy change is driven predominantly by the loss in the TS of degrees of freedom for translation and rotation of the reactants, leading to a rigid TS; the TS remains sufficiently reactant-like to suggest that entropy changes related to skeleton vibrations and internal rotors of the reactant moieties remain comparatively small. The potential energy profile of a typical CI + alkene reaction is shown in Scheme 1, while that for $\mathrm{CH}_{2} \mathrm{OO}+\mathrm{O}_{3}$ is shown in Scheme 4. In principle, such reaction schemes involving a pre-reactive complex ought to be treated 


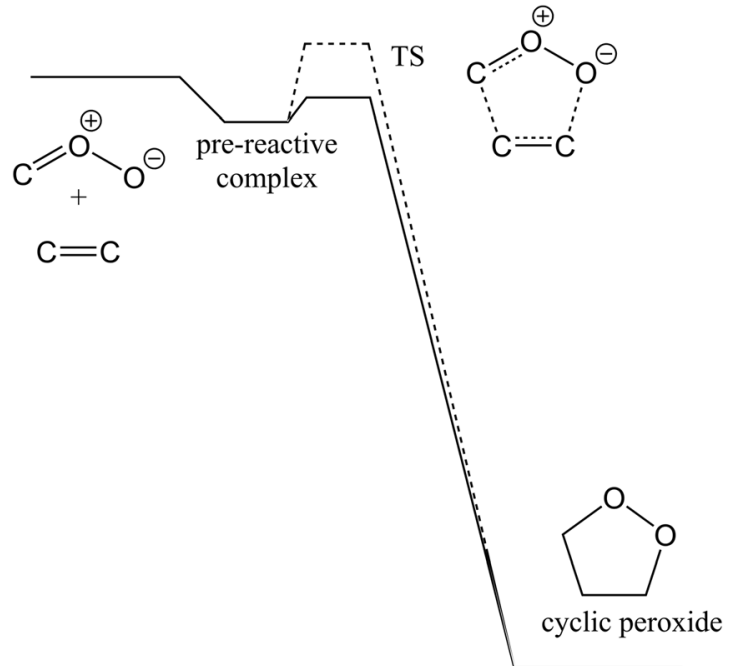

Scheme 1 Stylized representation of the potential energy surface of the reaction of $\mathrm{Cl}$ with alkenes, forming cyclic peroxides. The cycloaddition TS can be above (dotted line) or below the energy level of the separated reactants.

using a two-transition state model, with an "outer" TS for the formation of the pre-reactive complex and an "inner" TS for the addition, preferably in a Master Equation paradigm describing the collisional energy exchange of the complexes competing against the energy-specific redissociation or addition. The outer TS is essentially the long-range attraction between the reactants, with a high rate coefficient near the collision limit for formation of the complexes. The inner TS, on the other hand, is very rigid, with energy-specific rate coefficients well below those for redissociation or collisional energy transfer, making it the rate limiting step. As tunneling is negligible, the pre-reactive complex thus has little impact on the overall reaction kinetics. For a protruding inner TS, the complex cancels out the rate equations, but for a submerged inner TS, the population at the inner TS may not have a Maxwell-Boltzmann shape below the high-pressure limit. However, as the TS considered in this work is not too deeply submerged, we opt to still use thermal partition functions to describe the TS populations as a firstorder approximation.

To improve the rate estimation for the $\mathrm{CI}+$ alkene reactions, we performed rate calculations for the reaction of ozone with alkenes (see Table SI-1, ESI $\dagger$ ), for which extensive experimental rate data are available. ${ }^{37}$ As both the $\mathrm{O}_{3}$ and $\mathrm{CI}$ addition on alkenes share the 1,3-dipole cycloaddition mechanism, we can estimate the uncertainty on the rate predictions at the level of theory employed. The rate coefficients for $\mathrm{CI}+$ alkene rate coefficients are then scaled by the difference between the a priori predictions and the experimental observations for $\mathrm{O}_{3}+$ alkene; scaling factors are listed in Table SI-1 (ESI $\dagger$ ).

The reaction of $\mathrm{CH}_{2} \mathrm{OO}+\mathrm{CH}_{2} \mathrm{OO}$ was found to be barrierless. The reaction path was characterized by a large set of constrained geometry optimizations and frequency analyses along the minimum energy pathway at the M06-2X level of theory. The resulting energy profile and vibrational wavenumbers were used in micro-canonical variational transition state calculations to obtain the temperature-dependent rate coefficient, based on a rigid rotor harmonic oscillator approximation. Interpolation of the molecular characteristics between the characterized points along the reaction coordinate (RC) was done using cubic splines. The lowest predicted wavenumber, corresponding to a transitional degree of freedom, showed erratic behavior along the reaction coordinate due to numerical limitations in the optimization and frequency calculations; for this degree of freedom the wavenumber along the RC was smoothed following the profile of the other transitional degrees of freedom.

\section{$\mathrm{Cl}+$ alkenes}

\section{a. Reaction mechanism}

The reaction mechanism of the reaction of carbonyl oxides with alkenes is similar to the ozonolysis of alkenes, i.e. they belong to the class of 1,3-dipolar cycloadditions, showing a concerted pericyclic cycloaddition, as shown in Scheme 1. Both reactions proceed through a pre-reactive complex, and pass over a cyclic transition state that shows 6-electron Huckel aromatic properties; this rigid TS structure is the cause of the low entropy of activation and concomitant low reaction rates found for this type of reactions. ${ }^{37}$ The cyclic peroxide formed in CI + alkene reactions is significantly more stable than the cyclotrioxalane (the "primary ozonide", POZ) formed in the ozonolysis; the Evans-Polanyi principle suggests thus that a lower TS energy can be expected.

\section{b. Reaction barriers and rate coefficients}

Table 1 summarizes the stability of the pre-reactive complex, and the energy of the lowest TS for a series of CI + alkene reactions, while Table 2 lists the predicted total rate coefficients at room temperature. The $\mathrm{ESI} \dagger$ summarizes the reactivity trends (Fig. SI-1, ESI $\dagger$ ), and lists more extensive tables for all TS and complex conformers (Table SI-2, ESI $\dagger$ ). The CI and substrate compounds chosen play a smaller role in atmospheric chemistry, but serve as proxies for the larger biogenic terpenoids that constitute the bulk of the organic matter emitted into the atmosphere. The barrier heights for many of the CI + alkene reactions were found to be significantly lower than the corresponding ozonolysis reaction, in agreement with the work by Crehuet et al. ${ }^{23}$ and Lan et al. ${ }^{24}$ on $\mathrm{H}_{2} \mathrm{COO}$. Many of the reaction barriers we obtained for larger VOC and CI are below the energy of the free reactants.

\section{c. Error analysis}

The uncertainty on the predicted rate coefficients can be gauged by examining the rate coefficient of the ozonolysis reaction, a similar 1,3-dipole cycloaddition. Table SI-1 (ESI $\dagger$ ) lists the predicted rate coefficients at the various levels of theory, compares them to the experimental rate coefficient, ${ }^{37}$ and presents the scaling factor needed to bring the predicted rate coefficient in agreement with experiment. In all cases, higher levels of theory show improved performance. For small alkenes, the agreement is generally good even at the M06-2X level of theory, with scaling factors of less 
Table 1 ZPE-corrected energies relative to the separated reactants $\left(\mathrm{kcal} \mathrm{mol}^{-1}\right)$ of the pre-reactive complex and the cycloaddition transition state of a set of alkene $+\mathrm{Cl}$ reactions

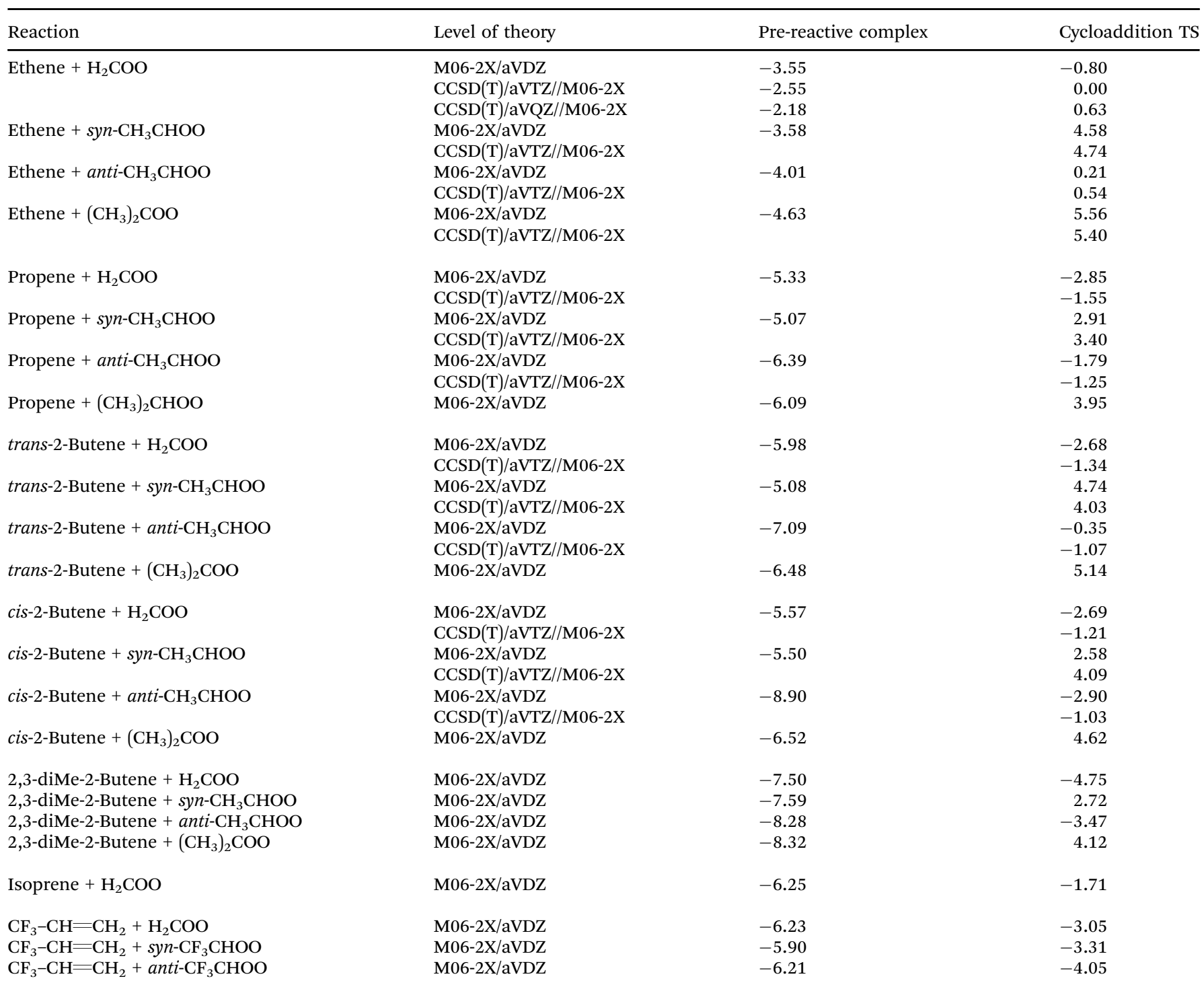

than 2. For larger alkenes, the agreement deteriorates somewhat, with scaling factors between 1.6 and 20; still, this corresponds to an error on the barrier height of less than $2 \mathrm{kcal} \mathrm{mol}^{-1}$, and systematic improvement of the level of theory should improve these numbers further. For trifluoropropene, we find a large discrepancy of 2 orders of magnitude. We therefore consider the calculations using this compound unreliable, and the values are listed only for reference purposes.

We should also consider that some of the reactions involve structures with a stronger multi-reference wavefunction than can be described by our chosen level of theory. The ESI $\dagger$ lists the $\mathrm{T} 1$ and/or D1 diagnostics for each of the structures, so that those most likely to be affected can be identified. Another source of error, which cannot be corrected for by comparison with ozonolysis, is the impact of the submerged barriers in many of these reactions. In all cases, we find rather low rate coefficients, well below the collision limit and the expected equilibration time between the pre-reactive complex and free reactants. As such, we feel that the reaction rate is likely not affected too much by our simplified kinetic treatment using only a single TS.

Overall, we estimate an uncertainty of an order of magnitude on the predicted rate coefficients, after scaling relative to the reference ozonolysis reaction. Improving the level of theory carries a significant computational cost; at this time, we prefer to wait for experimental evidence that the $\mathrm{CI}+$ alkene reaction can be relevant.

\section{d. Discussion}

We can distinguish three separate effects impacting the reaction rate of $\mathrm{CI}+$ alkene. First, for higher degrees of substitution on the alkenes, we find lower barriers to addition (e.g. $\mathrm{CH}_{2} \mathrm{OO}+$ ethene, propene, TME); this trend matches the well-known structure-activity relationship for ozonolysis. 
Table 2 Predicted rate coefficients $\left(\mathrm{cm}^{3}\right.$ molecule $\left.\mathrm{s}^{-1}\right)$ of the reactions of alkenes with $\mathrm{Cl}$ at the various levels of theory. Values given are the a priori values, and the values after scaling follow the scaling factor of the alkene ozonolysis reaction (see text)

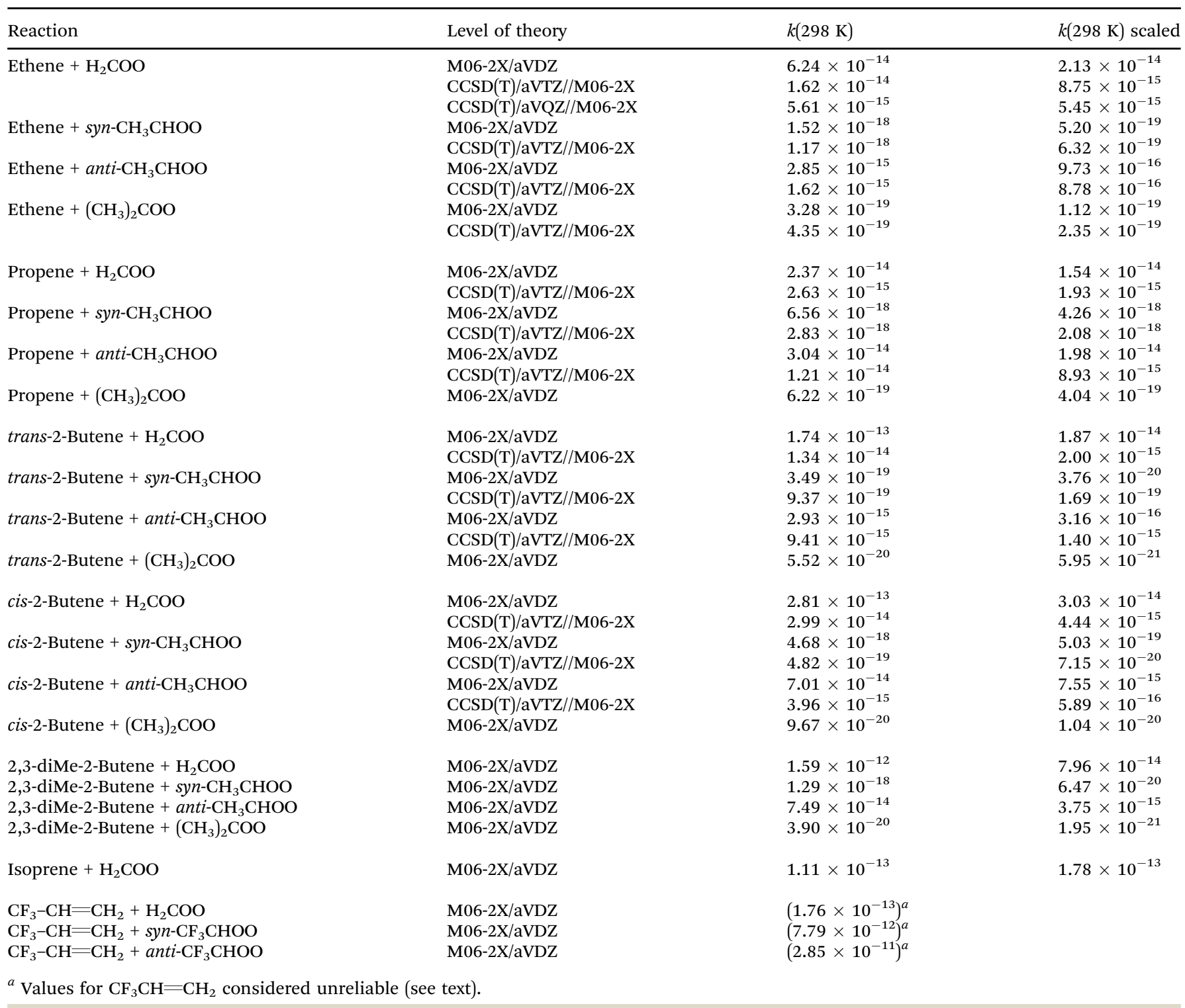

Second, and typically counteracting the first trend, we find that higher degrees of substitution on the alkene and/or CI result in strong steric hindrance between the substituents. This is illustrated clearly in the more detailed Table SI-2 (ESI $\dagger$ ), where different orientations of the reactants can lead to strongly differing barrier heights by up to $4 \mathrm{kcal} \mathrm{mol}^{-1}$. This hindrance thus induces a pronounced regio- and stereo-selectivity in the reaction of $\mathrm{CI}+$ alkenes, and furthermore effectively inhibits reactions of highly substituted CI such as $\left(\mathrm{CH}_{3}\right)_{2} \mathrm{COO}$. Third, we see a clear effect of the relative stability of different alkenes and CI conformers, e.g. syn/anti- $\mathrm{CH}_{3} \mathrm{CHOO}$ or cis/trans-2-butene as listed in Table 3. The transition state already has some degree of peroxide character, where the different conformers are not separated by significant energy differences. The potential energy in the higher-energy conformer of the CI or alkene can then lead to lower relative energies of the TS, though the
Table 3 Relative energies ( $\mathrm{kcal} \mathrm{mol}^{-1}$ ) of different conformers of alkene and aldehyde oxide at the levels of theory employed

\begin{tabular}{|c|c|c|}
\hline Compound & M06-2X/aVTZ & $\operatorname{CCSD}(\mathrm{T}) / \mathrm{aVTZ} / / \mathrm{M} 06-2 \mathrm{X}$ \\
\hline trans-2-Butene & 0.00 & 0.00 \\
\hline cis-2-Butene & 1.23 & 0.99 \\
\hline syn $-\mathrm{CH}_{3} \mathrm{CHOO}$ & 0.00 & 0.00 \\
\hline anti- $\mathrm{CH}_{3} \mathrm{CHOO}$ & 3.49 & 3.48 \\
\hline
\end{tabular}

absolute energy remains comparable to the lower-energy reactant conformer transition state.

The three interacting trends lead to widely differing rate coefficients. Generally, we conclude that towards alkenes, highly substituted $\mathrm{CI}$ will be non-reactive, $\mathrm{CH}_{2} \mathrm{OO}$ will be most reactive, and syn-CI are much less reactive than anti-CI. 


\section{$\mathrm{CH}_{2} \mathrm{OO}+\mathrm{O}_{3}$}

\section{a. Reaction mechanism}

Scheme 2 shows the PES of the reaction of $\mathrm{CH}_{2} \mathrm{OO}$ with $\mathrm{O}_{3}$ molecules, Table SI-3 (ESI $\dagger$ ) lists the relative energies of the individual intermediate and TS conformers, and Fig. SI-2 (ESI $\dagger$ ) shows the energy profile of the addition process. At large separation, the reaction of $\mathrm{CH}_{2} \mathrm{OO}$ with ozone molecules is governed by long-range electrostatic attraction between the partially charged atoms in the zwitterionic structures of both reactants. This results in the barrierless formation of a pre-reactive complex where the most stable complex conformer, with a stability of $-3.2 \mathrm{kcal} \mathrm{mol}^{-1}$, has no less than three electrostatic interactions (see Fig. 1): the two negatively charged outer oxygen atoms of $\mathrm{O}_{3}$ interact with the positively charged $\mathrm{CH}_{2}$ moiety in $\mathrm{CH}_{2} \mathrm{OO}$, while the positively charged central ozone oxygen interacts with the strongly negative outer oxygen of the CI. From this complex, a submerged TS for chain addition leads

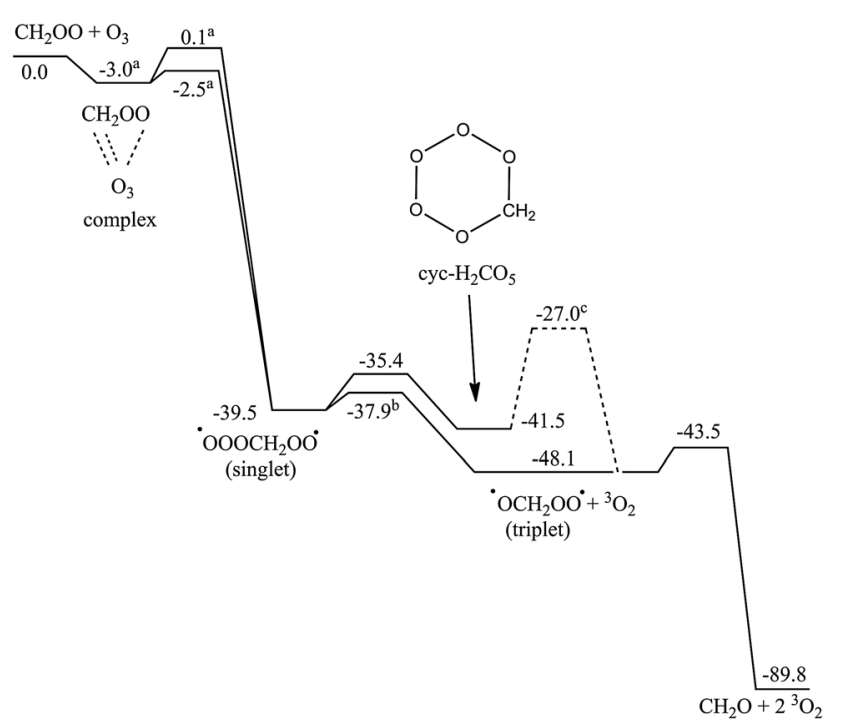

Scheme 2 ZPE-corrected potential energy surface of the reaction of $\mathrm{Cl}$ with ozone at the CCSD(T)/aVTZ//M06-2X level of theory $\left(\mathrm{kcal} \mathrm{mol}^{-1}\right)$. (a) At the $\operatorname{CCSD}(\mathrm{T}) /$ aug-Schwartz(DT)//M06-2X level of theory; (b) estimated from the M06-2X level of theory; (c) estimated from CCSD(T)//CCSD(T) calculations by Kjaergaard et al. ${ }^{20}$ but not found at the M06-2X level of theory.

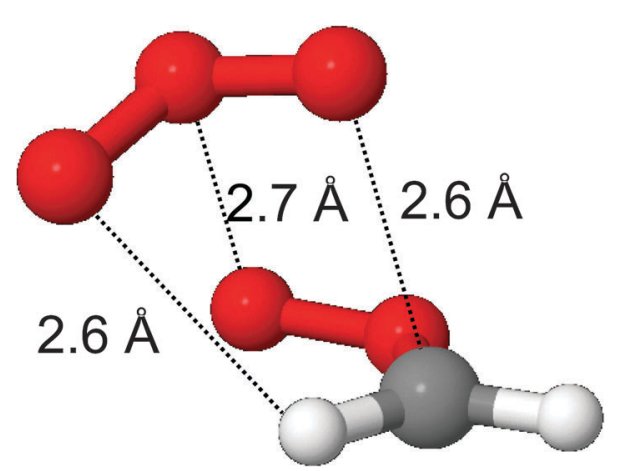

Fig. 1 A pre-reactive complex formed in the reaction of $\mathrm{H}_{2} \mathrm{COO}$ with $\mathrm{O}_{3}$. to the formation of a singlet ${ }^{\bullet} \mathrm{OOOCH}_{2} \mathrm{OO}{ }^{\bullet}$ bi-radical; two TS conformers were characterized. We have found no evidence for a direct cycloaddition channel forming cyc- $\mathrm{O}_{3} \mathrm{CH}_{2} \mathrm{O}_{2}-$, as proposed by Kjaergaard et al. ${ }^{20}$ Cycloaddition would involve the bonding of two negatively charged O-atoms from the reactants, which seems unlikely to proceed without a sizable barrier. Conversely, the chain addition pathway associating a negatively charged O-atom with the positively charged $\mathrm{CH}_{2}$ moiety seems to be the more plausible route mechanistically. The barrier for $\mathrm{O}_{3}$-addition from the complex is comparatively small, $0.35 \mathrm{kcal} \mathrm{mol}^{-1}$ at the $\operatorname{CCSD}(\mathrm{T}) / \mathrm{aVTZ}$ level of theory, but only $0.02 \mathrm{kcal} \mathrm{mol}^{-1}$ at the M06-2X level of theory and apparently non-existent at the B3LYP level of theory. We extrapolated the $\operatorname{CCSD}(\mathrm{T})$ energies from their aVDZ and aVTZ values to an infinite basis set (see Table SI-4, ESI $\dagger$ ) using the aug-Schwartz4(DT) method described by Martin. ${ }^{31}$ The barrier height relative to the complex increased to $0.44 \mathrm{kcal} \mathrm{mol}^{-1}$, at an energy $-2.5 \mathrm{kcal} \mathrm{mol}^{-1}$ below the free reactants.

The singlet ${ }^{\circ} \mathrm{OOOCH}_{2} \mathrm{OO}{ }^{\bullet}$ bi-radical can cyclize to cyc- $\mathrm{CH}_{2} \mathrm{O}_{5}{ }^{-}$ with a small energy barrier of $4 \mathrm{kcal} \mathrm{mol}^{-1}$. The entropically more favorable $\mathrm{O}_{2}$ elimination, however, forms triplet ${ }^{\bullet} \mathrm{OCH}_{2} \mathrm{OO}^{\bullet}$ which in turn readily eliminates $\mathrm{O}_{2}$ to form formaldehyde. Kjaergaard et al. ${ }^{20}$ characterized a direct $\mathrm{O}_{2}$ elimination TS from cyc- $\mathrm{CH}_{2} \mathrm{O}_{5}-$ forming triplet ${ }^{\bullet} \mathrm{OCH}_{2} \mathrm{OO}^{\bullet}$; we were unable to reproduce this channel at the M06-2X/aVTZ level of theory, and all efforts led to formation of ${ }^{\circ} \mathrm{OOOCH}_{2} \mathrm{OO}^{\bullet}$, which in turn could not be found using B3LYP.

The quantum chemical calculations proved very challenging, and obtaining the lowest energy SCF wave function required explicit care. Several intermediates and TSs were characterized, only to find that these were artifacts of incorrect SCF convergence. Of particular note is closed-shell TS for chain-addition at 0.64 and $9.0 \mathrm{kcal} \mathrm{mol}{ }^{-1}$ above the reactants. The main difference between the M06-2X results presented here and the PES by Kjaergaard et $a .^{20}$ based on the older B3LYP functional is the stability of the singlet ${ }^{\bullet} \mathrm{OOOCH}_{2} \mathrm{OO}^{\bullet}$ bi-radical. We prefer the ROCCSD(T)//M06-2X PES as it shows the expected features as already encountered for other CI reactions. ${ }^{4,19,21}$

\section{b. Discussion}

The internal energy afforded by the $\mathrm{O}_{3}$-addition on the $\mathrm{CI}$ carbon, combined with the low-lying TS for sequential $\mathrm{O}_{2}$ losses suggests that the product of the $\mathrm{CI}+\mathrm{O}_{3}$ reaction will always be the carbonyl compound $+2 \mathrm{O}_{2}$, irrespective of the CI substituents. The key parameter is therefore the rate coefficient of this reaction. In the assumption that the pre-reactive complex quickly equilibrates with the free reactants, we predict an overall rate coefficient of $1.0 \times 10^{-12} \mathrm{~cm}^{3}$ molecule ${ }^{-1} \mathrm{~s}^{-1}$ at room temperature. Especially for small CI, however, it seems likely that the reaction is in the low-pressure or fall-off regime, which would lower the overall rate coefficient somewhat due to a higher relative contribution of redissociation of the complex. This would also result in a weak pressure dependence. The rate coefficient shows a negative temperature dependence that can be described between $250-350 \mathrm{~K}$ by the Arrhenius expression $k(T)=3 \times 10^{-14} \exp (1068 / T)$, again assuming that the inner TS for chain addition is the rate limiting step, i.e. where complex redissociation is significantly faster. 
The uncertainty on the rate coefficient is conservatively estimated at up to an order of magnitude, until higher-level calculations are available to confirm the PES found in this work, and until the addition/redissociation competition for the complex has been characterized.

\section{$\mathrm{CH}_{2} \mathrm{OO}+\mathrm{CH}_{2} \mathrm{OO}$}

\section{a. Reaction mechanism}

Similar to the reaction of $\mathrm{CI}+\mathrm{O}_{3}$, the $\mathrm{CH}_{2} \mathrm{OO}+\mathrm{CH}_{2} \mathrm{OO}$ reaction is governed by strong electrostatic attraction at large reactant separation, driven by the zwitterionic character of the Criegee intermediates. The energy profile of cycloaddition, depicted in Fig. SI-3 (ESI $\dagger$ ), is purely attractive, without evidence for a pre-reactive complex or TS. The approach initially occurs in-plane, with an elongated hexagonal shape. A CI + CI approach with the central O-atom pointing toward the coreactant $\mathrm{CI}$ leads to broad energy barriers, and is not competitive. At intermediate distances, the Criegee intermediates rotate to present the $\pi$-system to their co-reactant, such that at short distances a symmetric, simultaneous double head-to-tail addition occurs, forming two new $\mathrm{C}-\mathrm{O}$ bonds. This highly exothermic reaction forms a six-membered cyclic biperoxide (see Scheme 3) at an M06-2X energy of $\sim-100 \mathrm{kcal} \mathrm{mol}^{-1}$. We also characterized a cyclic $-\mathrm{O}_{2} \mathrm{CH}_{2} \mathrm{CH}_{2} \mathrm{O}_{2}$ - intermediate, and examined part of its subsequent chemistry (see Scheme SI-1, ESI $\dagger$ ). However, even after discounting the much lower exothermicity, such a head-to-head addition involves a high energy barrier of at least $10 \mathrm{kcal} \mathrm{mol}^{-1}$, owing to the need to overcome the electrostatic repulsion between similarly charged atoms. For similar reasons, we

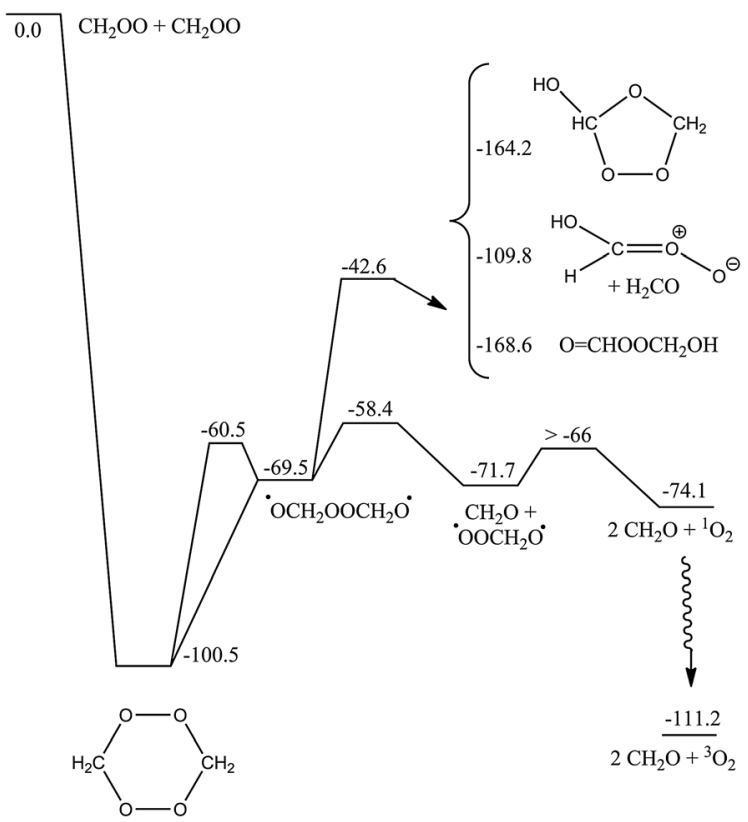

Scheme 3 ZPE-corrected potential energy surface $\left(\mathrm{kcal} \mathrm{mol}^{-1}\right)$ of the $\mathrm{CH}_{2} \mathrm{OO}+\mathrm{CH}_{2} \mathrm{OO}$ head-to-tail cycloaddition reaction at the M06-2X level of theory. All biradicals are in their singlet state, except ${ }^{3} \mathrm{O}_{2}$. Partial $\operatorname{CCSD}(\mathrm{T}) / / \mathrm{M} 06-2 \mathrm{X}$ energies are available in the $\mathrm{ESI}, \dagger$ as is a partial PES for head-to-head (cyclo)addition. reject a carbon-to-carbon chain-addition mechanism. The cyc$\mathrm{O}_{2} \mathrm{CH}_{2} \mathrm{CH}_{2} \mathrm{O}_{2}$ - reaction branch is therefore likely superfluous.

The subsequent chemistry of the biperoxide, shown in Scheme 3, involves chemically activated breaking of the weaker $\mathrm{O}-\mathrm{O}$ bonds, forming a singlet peroxide bisalkoxy radical - $\mathrm{OCH}_{2} \mathrm{OOCH}_{2} \mathrm{O}$, which can eliminate $\mathrm{CH}_{2} \mathrm{O}$, forming singlet - $\mathrm{OOCH}_{2} \mathrm{O}^{\bullet}$, which in turn can dissociate to $\mathrm{CH}_{2} \mathrm{O}+\mathrm{O}_{2}\left({ }^{1} \mathrm{D}\right)$ with an overall exothermicity of over $70 \mathrm{kcal} \mathrm{mol}^{-1}$. There are several higher-energy pathways accessible. Similar to the chemistry recently proposed ${ }^{21}$ for CI + carbonyl compounds, 1,5-H-migration reactions can form the $\mathrm{OCHOOCH}_{2} \mathrm{OH}$ intermediate. A 1,2-H-shift, followed by rapid cyclization or decomposition can form a hydroxy-substituted secondary ozonide, or an anti-hydroxy-CI $+\mathrm{H}_{2} \mathrm{CO}$. The chemically activated intermediates, in turn, allow access to a rich chemistry forming acids, peracids and carbonyl compounds (see Scheme 4). In agreement with earlier work by Selçuki and Aviyente ${ }^{38}$ we find that $s y n$-hydroxy-CI are unstable and isomerise to a peracid.

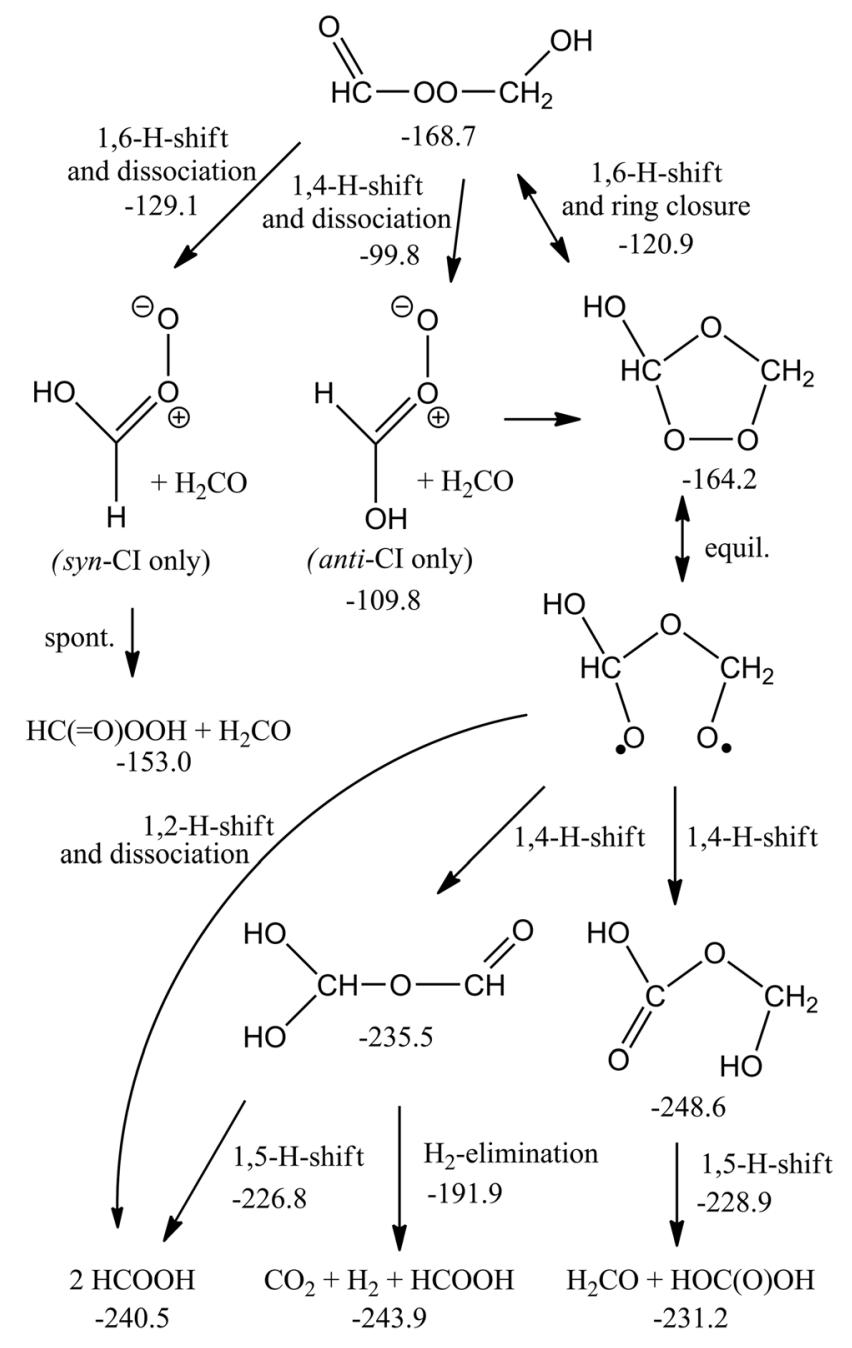

Scheme 4 Reactions and products accessible through $\mathrm{H}$-migration reactions in the ${ }^{\bullet} \mathrm{OCH}_{2} \mathrm{OOCH}_{2} \mathrm{O}^{\bullet}$ biradical. Numbers indicate $\mathrm{ZPE}$-corrected M06-2X/aug-cc-pVTZ relative energies $\left(\mathrm{kcal} \mathrm{mol}^{-1}\right)$ relative to the free reactants. 
$\operatorname{CCSD}(\mathrm{T}) / / \mathrm{M} 06-2 \mathrm{X}$ relative energies of a subset of structures are also available in Table SI-5 (ESI $\dagger$ ).

\section{b. Discussion}

Variational microcanonical TST predictions of the rate coefficient yield $k(300 \mathrm{~K})=\sim 3.8 \times 10^{-11} \mathrm{~cm}^{3}$ molecule ${ }^{-1} \mathrm{~s}^{-1}$, constant within $20 \%$ over the $250 \mathrm{~K}$ to $350 \mathrm{~K}$ interval. The kinetic bottleneck is found at very large separations, $\sim 7-8 \AA$, where the electrostatic complex starts to form and becomes rigid. The predicted rate depends on the characteristics of the transitional degrees of freedom at these distances, as well as on the strength of the attractive potential at the M06-2X level of theory; we suspect that this rate coefficient is an underestimation. Overall, the uncertainty on the rate coefficient is estimated at a factor of 5. The recent direct IR-absorption measurements of Su et al. ${ }^{14}$ show a fast decay in the $\mathrm{CH}_{2} \mathrm{OO}$ absorption signal, which was also attributed to fast $\mathrm{CI}+\mathrm{CI}$ reactions; our predictions for a fast reaction rate approaching the collision limit are thus supported by these observations.

For smaller CI, the adduct will predominantly dissociate into carbonyl compounds $+\mathrm{O}_{2}\left({ }^{1} \mathrm{D}\right)$. For larger CI, such as those formed from terpenoids, we should consider collisional stabilization of the cyclic biperoxide as well. The high nascent energy content could also enable other isomerisation or decomposition channels; examples include the formation of acids by internal H-migration as already proposed in the $\mathrm{CI}+\mathrm{SO}_{2}$ and $\mathrm{CI}+$ carbonyl reactions. ${ }^{4,21}$ Scheme 4 shows a set of reactions that are accessible through this H-migration; the intermediates formed have internal energies as high as $250 \mathrm{kcal} \mathrm{mol}^{-1}$, which ensure very fast isomerisation and/or dissociation even for very large CI. A Master Equationbased product analysis is deferred to a future publication, as is a study of the dependence of this chemistry on the CI substituents. Compared to the CI + carbonyl reactions recently studied by Jalan et al. ${ }^{21}$ the isomerisation channels lie significantly lower compared to the free reactants, and contribution of these channels can be expected to be larger than for secondary ozonides, and remain relevant at higher pressures.

\section{Box modeling of experimental reaction conditions}

To illustrate the importance of the title reactions, we show the results of a modeling study of an ozonolysis experiment ${ }^{39}$ of trans2-butene. 2-Butene $\left(1.8 \times 10^{15}\right.$ molecules $\left.\mathrm{cm}^{-3}\right)$, ozone $(1.0 \times$ $10^{13}$ molecules $\left.\mathrm{cm}^{-3}\right)$, and propane $\left(2.5 \times 10^{16}\right.$ molecules $\left.\mathrm{cm}^{-3}\right)$ were mixed in a flow tube with 1 atm of $\mathrm{N}_{2}$ carrier gas with $4 \%$ of $\mathrm{O}_{2}$, and allowed to react for $2.5 \mathrm{~s}$ prior to sampling through a steel nozzle into a low-pressure FAGE system (Fluorescence Assay by Gas Expansion) where the temporal formation of $\mathrm{OH}$ from $s y n-\mathrm{CH}_{3} \mathrm{CHOO}$ decomposition was measured. A detailed description of this experimental study ${ }^{39}$ will be presented in separate publications; for our current purposes we are interested mainly in the prediction of the steady-state concentration of the CI, and specifically reactions that influence this concentration. The key result in this respect is that we are able to
Table 4 Rate coefficients of reactions of Criegee intermediates under laboratory and atmospheric reaction conditions

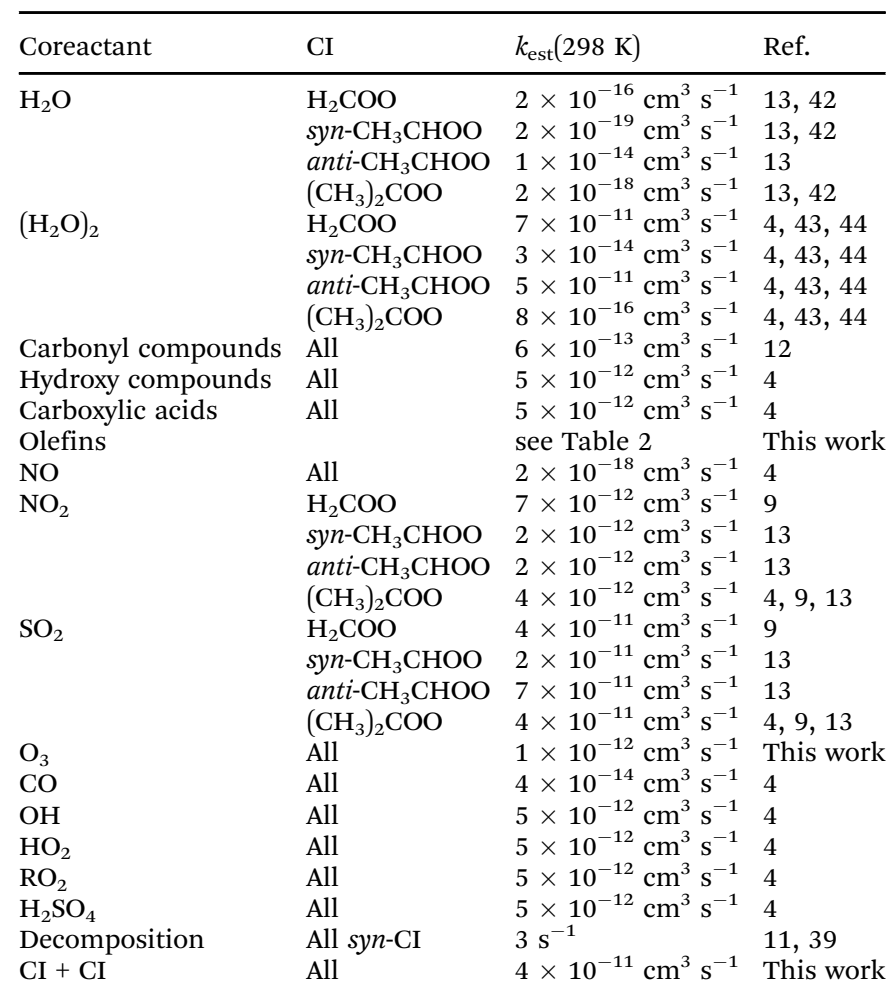

predict, quantitatively and without further fitting, the full time-dependent $\mathrm{OH}$ profile generated by $\mathrm{CI}$ decomposition as measured within the FAGE instrument, by applying the Master Chemical Mechanism (MCM 3.2) ${ }^{40,41}$ obtained from website http://mcm.leeds.ac.uk/MCM, supplemented with literature values and estimates for stabilized CI chemistry (Table 4). The quantitative agreement indicates that the CI concentration predicted in the flow tube at the sampling point is reproduced correctly by the model. The few additions to the MCM are the syn- and antispecific reactions of $\mathrm{CH}_{3} \mathrm{CHOO}$ with carbonyl- ${ }^{4,12}$ hydroxy- ${ }^{4}$ and carboxylic compounds; ${ }^{4}$ their reaction with $\mathrm{HO}_{2}$ and $\mathrm{RO}_{2} ;{ }^{4,19}$ the reaction of CI with $\mathrm{O}_{3}$, CI, and alkenes as characterized in this work; the IUPAC-recommended yield of 0.18 for stabilized $\mathrm{CI}{ }^{37}$ an estimated nascent $3: 1$ syn- to anti-ratio of stabilized $\mathrm{CH}_{3} \mathrm{CHOO}$ (in line with their relative energies); and a thermal decomposition rate of $3 \mathrm{~s}^{-1}$ for $s y n-\mathrm{CH}_{3} \mathrm{CHOO}$ as obtained by Berndt et al. ${ }^{11}$ For the low-pressure section in the FAGE instruments, wall losses of $\mathrm{OH}$ were measured at $65 \mathrm{~s}^{-1}$, while wall loss of CI was estimated to be similar to that measured for $\mathrm{HO}_{2}, 20 \mathrm{~s}^{-1}$. Fig. 2 shows the absolute contributions of CI sources and sinks in the $1 \mathrm{~atm}$ flow tube chemistry, while Fig. SI-4 (ESI $\dagger$ ) shows the concentrationtime profiles. We find that a multitude of reactions govern the predicted steady-state concentration of the CI, not only the unimolecular decomposition but also the reactions of CI with oxygenated intermediates, the reaction of $\mathrm{CI}+\mathrm{O}_{3}$, and the $\mathrm{CI}+\mathrm{CI}$ and $\mathrm{CI}+\mathrm{HO}_{2} / \mathrm{RO}_{2}$ reactions. The relative contributions of these channels change over time, with e.g. $\mathrm{O}_{3}$ being important mostly at the reaction start when its concentration is still high, 


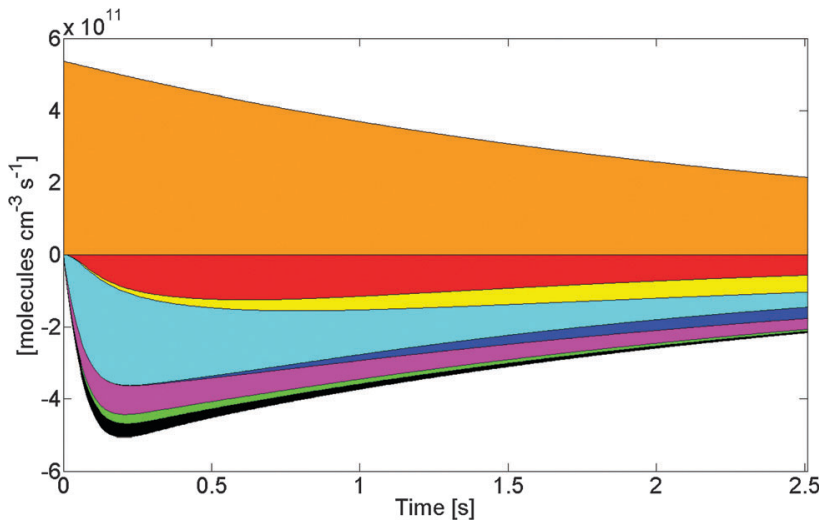

Fig. 2 Absolute contribution of the reactions affecting the concentration of syn- $\mathrm{CH}_{3} \mathrm{CHOO}$ in the ozonolysis of trans-2-butene by at least $1 \%$. Formation (positive contribution) via 2 -butene $+\mathrm{O}_{3}$ is exclusive. Destruction reactions (negative contributions), shown cumulatively from zero downward in decreasing order of importance at the sample point at $2.5 \mathrm{~s}$, are $\mathrm{RO}_{2}$ (red), carbonyl compounds (yellow), $\mathrm{O}_{3}$ (light blue), hydroxy compounds (dark blue), unimolecular decomposition to $\mathrm{OH}$ (cyan), $\mathrm{HO}_{2}$ (green), and $\mathrm{Cl}+\mathrm{Cl}$ (black)

while the contributions of oxygenates increase as they are formed in the secondary chemistry. While the impact of each reaction on the CI concentration is limited, and subject to large uncertainties, it is also manifest that neglecting the summed contribution of these non-traditional CI chemical loss processes would lead to an incorrect prediction of the CI steady state concentration, and hence would induce a systematic disagreement between the kinetic model and experimental observations.

\section{Contributions under atmospheric conditions}

In earlier work we analyzed the relative contribution of many coreactants in the atmosphere to the atmospheric fate of a set of CI intermediates, ranging from the simplest $\mathrm{CH}_{2} \mathrm{OO}$ to isoprene-derived SCI. ${ }^{4}$ Table 4 shows an updated list of rate coefficients, where the main modifications compared to Vereecken et $a l_{.}{ }^{4}$ are (i) updated values of the CI-specific rate coefficients with $\mathrm{H}_{2} \mathrm{O}$ and $\left(\mathrm{H}_{2} \mathrm{O}\right)_{2}$, where we employ the relative rate predictions by Anglada et al. ${ }^{42}$ and Ryzhkov and Ariya ${ }^{43}$ scaled to match the absolute value for anti- $\mathrm{CH}_{3} \mathrm{CHOO}+\mathrm{H}_{2} \mathrm{O}$ as measured by Taatjes et al., ${ }^{13}$ (ii) the lumped rate coefficient of $\mathrm{CI}+$ carbonyl compounds was changed to $6 \times 10^{-13} \mathrm{~cm}^{3}$ molecule $\mathrm{s}^{-1}$ based on the measurements of Taatjes et al., ${ }^{12}$ and (iii) inclusion of the $\mathrm{CI}+\mathrm{O}_{3}$ reaction as studied in this work. Table 5 lists the predicted contributions of the various loss processes in different environments as defined earlier by Vereecken et $a l .{ }^{4}$ Compared to these earlier estimates, the lower rate coefficient of reaction with water opens the possibility for higher contributions of other CI loss processes; we also find that our current prediction of the $\mathrm{CI}+\mathrm{O}_{3}$ reaction rate makes this channel competitive.
Table 5 Loss path contributions (fraction) as a function of $\mathrm{Cl}$ substituents and environment

\begin{tabular}{|c|c|c|c|c|}
\hline Loss path & $\begin{array}{l}\text { Boreal } \\
\text { forest }\end{array}$ & $\begin{array}{l}\text { Tropical } \\
\text { forest }\end{array}$ & $\begin{array}{l}\text { Mega } \\
\text { city }\end{array}$ & $\begin{array}{l}\text { Rural } \\
\text { Europe }\end{array}$ \\
\hline \multicolumn{5}{|l|}{$\mathrm{H}_{2} \mathrm{COO}$} \\
\hline $\mathrm{H}_{2} \mathrm{O}$ & 0.01 & & 0.01 & 0.01 \\
\hline$\left(\mathrm{H}_{2} \mathrm{O}\right)_{2}$ & 0.99 & 1.00 & 0.99 & 0.99 \\
\hline \multicolumn{5}{|l|}{ anti- $\mathrm{CH}_{3} \mathrm{CHOO}$} \\
\hline $\mathrm{H}_{2} \mathrm{O}$ & 0.25 & 0.18 & 0.35 & 0.26 \\
\hline$\left(\mathrm{H}_{2} \mathrm{O}\right)_{2}$ & 0.75 & 0.82 & 0.64 & 0.74 \\
\hline Ester channel & & & 0.01 & \\
\hline \multicolumn{5}{|l|}{ syn $-\mathrm{CH}_{3} \mathrm{CHOO}$} \\
\hline $\mathrm{H}_{2} \mathrm{O}$ & 0.01 & 0.01 & & 0.01 \\
\hline$\left(\mathrm{H}_{2} \mathrm{O}\right)_{2}$ & 0.54 & 0.81 & 0.15 & 0.58 \\
\hline VHP channel & 0.22 & 0.14 & 0.16 & 0.26 \\
\hline $\mathrm{NO}_{2}$ & & & 0.10 & 0.01 \\
\hline $\mathrm{SO}_{2}$ & 0.05 & & 0.20 & 0.02 \\
\hline $\mathrm{O}_{3}$ & 0.07 & 0.02 & 0.12 & 0.12 \\
\hline Carbonyl compounds & 0.01 & & 0.02 & \\
\hline Carboxylic acids & 0.04 & 0.01 & & \\
\hline Hydroxyl-compounds & 0.06 & 0.01 & 0.25 & \\
\hline \multicolumn{5}{|l|}{$\left(\mathrm{CH}_{3}\right)_{2} \mathrm{COO}$} \\
\hline $\mathrm{H}_{2} \mathrm{O}$ & 0.11 & 0.22 & 0.03 & 0.13 \\
\hline$\left(\mathrm{H}_{2} \mathrm{O}\right)_{2}$ & 0.03 & 0.08 & & 0.03 \\
\hline VHP channel & 0.43 & 0.54 & 0.19 & 0.52 \\
\hline $\mathrm{NO}_{2}$ & & & 0.11 & 0.02 \\
\hline $\mathrm{SO}_{2}$ & 0.10 & & 0.22 & 0.05 \\
\hline $\mathrm{O}_{3}$ & 0.14 & 0.08 & 0.14 & 0.24 \\
\hline Carbonyl compounds & 0.01 & & 0.02 & 0.01 \\
\hline Carboxylic acids & 0.07 & 0.04 & & \\
\hline Hydroxyl-compounds & 0.11 & 0.04 & 0.29 & \\
\hline
\end{tabular}

\section{Conclusions}

In this work, we characterized the reactions of CI with alkenes, $\mathrm{CH}_{2} \mathrm{OO}$, and $\mathrm{O}_{3}$. We find that the reaction of CI with olefines is highly dependent on substitution in the alkene and CI, with very large differences in the predicted rate coefficients. The predicted reaction rates indicate that the $\mathrm{CI}+$ alkene reaction will have a small to negligible influence on the CI chemistry, both in the atmosphere and in experimental work, except perhaps at the highest concentrations of alkenes. The reaction of $\mathrm{CI}+\mathrm{O}_{3}$ was found to be relatively fast, proceeding through a pre-reactive complex and a submerged barrier, and leading to the formation of a carbonyl compound and oxygen molecules. The predicted rate coefficient carries a large uncertainty, but our current best estimate indicates that this reaction can influence both atmospheric CI chemistry and laboratory work. The $\mathrm{CH}_{2} \mathrm{OO}+\mathrm{CH}_{2} \mathrm{OO}$ reaction is extremely fast, proceeding with a rate near the collision limit without evidence of an energy barrier. The low concentrations of CI in the atmosphere limit the impact of this reaction to experimental conditions where higher CI-concentrations can be generated.

We recommend that both the $\mathrm{CI}+\mathrm{O}_{3}$ reaction and the $\mathrm{CI}+\mathrm{CI}$ reaction be further investigated by experimental means, and theoretically using even higher levels of methodologies. Particularly the CI loss by reaction with $\mathrm{O}_{3}$ in the atmosphere might affect the ambient concentration of $\mathrm{CI}$, and hence reduce the impact of CI chemistry currently proposed for $\mathrm{H}_{2} \mathrm{SO}_{4}$ formation or the $\mathrm{NO}_{x}$ cycle. 


\section{Acknowledgements}

LV is supported by the Max Planck Graduate Center with the Johannes Gutenberg-Universität Mainz (MPGC).

\section{References}

1 R. Criegee and G. Wenner, Justus Liebigs Ann. Chem., 1949, 564, 9-15.

2 R. Criegee, Angew. Chem., Int. Ed. Engl., 1975, 14, 745-752.

3 C. A. Taatjes, D. E. Shallcross and C. Percival, Phys. Chem. Chem. Phys., 2013, 16, 1704-1718.

4 L. Vereecken, H. Harder and A. Novelli, Phys. Chem. Chem. Phys., 2012, 14, 14682-14695.

5 G. Marston, Science, 2012, 335, 178-179.

6 L. Vereecken, Science, 2013, 340, 154-155.

7 C. Percival, O. Welz, A. J. Eskola, J. D. Savee, D. L. Osborn, D. O. Topping, D. Lowe, S. Utembe, A. Bacak, G. McFiggans, M. Cooke, A. T. Archibald, M. Jenkin, R. G. Derwent, I. Riipinen, D. Mok, E. P. F. Lee, J. Dyke, C. A. Taatjes and D. E. Shallcross, Faraday Discuss., 2013, 165, 45-73.

8 C. A. Taatjes, G. Meloni, T. M. Selby, A. J. Trevitt, D. L. Osborn, C. J. Percival and D. E. Shallcross, J. Am. Chem. Soc., 2008, 130, 11883-11885.

9 O. Welz, J. D. Savee, D. L. Osborn, S. S. Vasu, C. J. Percival, D. E. Shallcross and C. A. Taatjes, Science, 2012, 335, 204-207.

10 R. L. Mauldin III, T. Berndt, M. Sipilä, P. Paasonen, T. Petäjä, S. Kim, T. Kurtén, F. Stratmann, V.-M. Kerminen and M. Kulmala, Nature, 2012, 488, 193-196.

11 T. Berndt, T. Jokinen, R. L. Mauldin, T. Petäjä, H. Herrmann, H. Junninen, P. Paasonen, D. R. Worsnop and M. Sipilä, J. Phys. Chem. Lett., 2012, 3, 2892-2896.

12 C. A. Taatjes, O. Welz, A. J. Eskola, J. D. Savee, D. L. Osborn, E. P. F. Lee, J. M. Dyke, D. W. K. Mok, D. E. Shallcross and C. J. Percival, Phys. Chem. Chem. Phys., 2012, 14, 10391-10400.

13 C. A. Taatjes, O. Welz, A. J. Eskola, J. D. Savee, A. M. Scheer, D. E. Shallcross, B. Rotavera, E. P. F. Lee, J. M. Dyke, D. K. W. Mok, D. L. Osborn and C. J. Percival, Science, 2013, 340, 177-180.

14 Y.-T. Su, Y.-H. Huang, H. A. Witek and Y.-P. Lee, Science, 2013, 340, 174-176.

15 J. M. Beames, F. Liu, L. Lu and M. I. Lester, J. Am. Chem. Soc., 2012, 134, 20045-20048.

16 J. M. Beames, F. Liu, L. Lu and M. I. Lester, J. Chem. Phys., 2013, 138, 244307.

17 B. Ouyang, M. W. McLeod, R. L. Jones and W. J. Bloss, Phys. Chem. Chem. Phys., 2013, 15, 17070-17075.

18 M. Nakajima and Y. Endo, J. Chem. Phys., 2013, 139, 101103.

19 L. Vereecken and J. S. Francisco, Chem. Soc. Rev., 2012, 41, 6259-6293.

20 H. G. Kjaergaard, T. Kurtén, L. B. Nielsen, S. Jørgensen and P. O. Wennberg, J. Phys. Chem. Lett., 2013, 2525-2529.

21 A. Jalan, J. W. Allen and W. H. Green, Phys. Chem. Chem. Phys., 2013, 15, 16841-16852.
22 W. Sander, Angew. Chem., Int. Ed. Engl., 1990, 29, 344-354.

23 R. Crehuet, J. M. Anglada, D. Cremer and J. M. Bofill, J. Phys. Chem. A, 2002, 106, 3917-3929.

24 Y. Lan, L. Zou, Y. Cao and K. N. Houk, J. Phys. Chem. A, 2011, 115, 13906-13920.

25 W. H. Bunnelle, Chem. Rev., 1991, 91, 335-362.

26 P. R. Story and J. R. Burgess, J. Am. Chem. Soc., 1967, 89, 5726-5727.

27 Y. Zhao and D. G. Truhlar, Theor. Chem. Acc., 2008, 120, 215-241.

28 T. H. Dunning, J. Chem. Phys., 1989, 90, 1007-1023.

29 I. M. Alecu, J. Zheng, Y. Zhao and D. G. Truhlar, J. Chem. Theory Comput., 2010, 6, 2872-2887.

30 J. Zheng, I. M. Alecu, B. J. Lynch, Y. Zhao and D. G. Truhlar, Database of Frequency Scale Factors for Electronic Model Chemistries, http://comp.chem.umn.edu/freqscale/index.html. 31 J. M. L. Martin, Chem. Phys. Lett., 1996, 259, 669-678.

32 L. Noodleman, J. Chem. Phys., 1981, 74, 5737-5743.

33 J. C. Rienstra-Kiracofe, W. D. Allen and H. F. Schaefer, J. Phys. Chem. A, 2000, 104, 9823-9840.

34 M. J. Frisch, G. W. Trucks, H. B. Schlegel, G. E. Scuseria, M. A. Robb, J. R. Cheeseman, G. Scalmani, V. Barone, B. Mennucci, G. A. Petersson, H. Nakatsuji, M. Caricato, X. Li, H. P. Hratchian, A. F. Izmaylov, J. Bloino, G. Zheng, J. L. Sonnenberg, M. Hada, M. Ehara, K. Toyota, R. Fukuda, J. Hasegawa, M. Ishida, T. Nakajima, Y. Honda, O. Kitao, H. Nakai, T. Vreven, J. A. Montgomery Jr., J. E. Peralta, F. Ogliaro, M. Bearpark, J. J. Heyd, E. Brothers, K. N. Kudin, V. N. Staroverov, T. Keith, R. Kobayashi, J. Normand, J. Normand, K. Raghavachari, A. Rendell, J. C. Burant, S. S. Iyengar, J. Tomasi, M. Cossi, N. Rega, J. M. Millam, M. Klene, J. E. Knox, J. B. Cross, V. Bakken, C. Adamo, J. Jaramillo, R. Gomperts, R. E. Stratmann, O. Yazyev, A. J. Austin, R. Cammi, C. Pomelli, J. W. Ochterski, R. L. Martin, K. Morokuma, V. G. Zakrzewski, G. A. Voth, P. Salvador, J. J. Dannenberg, S. Dapprich, A. D. Daniels, O. Farkas, J. B. Foresman, J. V. Ortiz, J. Cioslowski, D. J. Fox and J. A. Pople, Gaussian 09, Revision B.01, Gaussian Inc., Wallington CT, 2010.

35 H.-J. Werner, P. J. Knowles, G. Knizia, F. R. Manby, M. Schütz, P. Celani, T. Korona, R. Lindh, A. Mitrushenkov, G. Rauhut, K. R. Shamasundar, T. B. Adler, R. D. Amos, A. Bernhardsson, A. Berning, D. L. Cooper, M. J. O. Deegan, A. J. Dobbyn, F. Eckert, E. Goll, C. Hampel, A. Hesselmann, G. Hetzer, T. Hrenar, G. Jansen, C. Köppl, Y. Liu, A. W. Lloyd, R. A. Mata, A. J. May, S. J. McNicholas, W. Meyer, M. E. Mura, A. Nicklass, D. P. O’Neill, P. Palmieri, K. Pflüger, R. Pitzer, M. Reiher, T. Shiozaki, H. Stoll, A. J. Stone, R. Tarroni, T. Thorsteinsson, M. Wang and A. Wolf, MOLPRO, version 2010.1, a package of ab initio programs, molpro, 2010.

36 Jmol: an open-source Java viewer for chemical structures in 3D, http://www.jmol.org.

37 R. Atkinson, D. L. Baulch, R. A. Cox, J. N. Crowley, R. F. Hampson, R. G. Hynes, M. E. Jenkin, M. J. Rossi, J. Troe and IUPAC Subcommittee, Atmos. Chem. Phys., 2006, 6, 3625-4055. 
38 C. Selçuki and V. Aviyente, THEOCHEM, 2000, 530, 97-107.

39 A. Novelli, K. Hens, C. Tatum Ernest, K. Trawny, M. Rudolf, Z. Hosaynali-Beygi, H. Fischer, J. Williams, L. Vereecken, M. Martinez, J. Lelieveld, H. Harder, P. Paasonen, M. Sipilä, P. Keronen, T. Petäjä, T. Elste, C. Plass-Dülmer and D. Kubistin, Assessment of the role of stabilized Criegee intermediates in the $\mathrm{OH}$ radical measurements by LIF, Atmos. Chem. Mechanisms Conference, Davis, CA, USA, 2012.
40 M. E. Jenkin, S. M. Saunders and M. J. Pilling, Atmos. Environ., 1997, 31, 81-104.

41 S. M. Saunders, M. E. Jenkin, R. G. Derwent and M. J. Pilling, Atmos. Chem. Phys., 2003, 3, 161-180.

42 J. M. Anglada, J. González and M. Torrent-Sucarrat, Phys. Chem. Chem. Phys., 2011, 13, 13034-13045.

43 A. B. Ryzhkov and P. A. Ariya, Phys. Chem. Chem. Phys., 2004, 6, 5042-5050.

44 A. B. Ryzhkov and P. A. Ariya, Chem. Phys. Lett., 2003, 367, 423-429. 